\title{
Telafi ve Etkinlik Hipotezlerinin MINT Ülkeleri için Geçerliliğinin İncelenmesi
}

\author{
Examination of the Validity of the Compensation and Efficiency \\ Hypothesis for MINT Countries
}

\section{Asiye Tütüncü - Prof. Dr. Hilmi Zengin}

Başvuru Tarihi: 21.11.2017

Kabul Tarihi: 24.12.2018

\section{Öz}

Ülkelerin dışa açıklık derecelerinin artması, karşılaştıkları ekonomik riskleri de arttırmaktadir. Bu risklerin önlenmesi ülkelerin ekonomide sahip olduğu kamu büyüklüğ̈̈ ile ilgilidir. Literatürde dışa açıklık ve kamu büyüklüğ̈̈ arasindaki ilişki ise, telafi ve etkinlik hipotezleri altında incelenmektedir. Bu çalışmada söz konusu hipotezleri test etmek için, kamunun ekonomideki büyüklüğünü ifade eden kamu harcamaları ve dişa açıklık derecesi arasındaki ilişki incelenmiştir. Bu amaçla MINT ülkeleri, Meksika, Endonezya, Nijerya ve Türkiye, için 1987 - 2015 dönemi ylllk veri seti, Çok Kırılmalı Panel Eşbütünleşme Testi kullanılarak araștırilmıştır. Elde edilen sonuçlara göre, kamu harcamala$r$ ve dişa açıklik arasında istatistiksel olarak anlamlı bir eşbütünleşme ilişkisi vardır. CCE katsay tahmincisine göre ise, Meksika ve Türkiye için dışa açılmadan kaynaklanan risklerin devlet tarafindan telafi edildiğ $i$ sonucuna ulaşılmıştır. Endonezya ve Nijerya için ise, dişa açılmanın kamu harcamalarını negatif etkilediğini ileri süren etkinlik hipotezi desteklenmektedir.

Anahtar Kelimeler: Telafi hipotezi, Etkinlik Hipotezi, Çok Kırılmalı Panel Eşbütünleşme Testi

\begin{abstract}
The increase in trade openness of countries also increase the economic risks. Prevention of these risks is related to government size countries have in their economy. The relationship between trade openness and government size is examined under the compensation and efficiency hypothesis. In this study, to testing theoretical hypothesis investigated the relationship between government spending that means government size in economy and trade openness. This purpose annual data for the period of 1987-2015 for MINT countries, Mexico, Indonesia, Nigeria and Turkey, are tested by using Panel Cointegration with Multiple Structural Breaks. According to the results, there is a cointegration relationship between government spending and trade openness. The cointegration vector coefficients estimated using CCE show that risks from trade openness are compensated by government and government spending encourage trade openness for Mexico and Turkey. Efficiency hypothesis means trade openness is negatively effected government spending is supported for Indonesia and Nigeria.
\end{abstract}

Keywords: Compensation Hypothesis, Efficiency Hypothesis, Panel Cointegration with Multiple Structural Breaks

Asiye Tütüncü, Karadeniz Teknik Üniversitesi Sosyal Bilimler Enstitüsü, asiyetutuncu@ktu.edu.tr, ORCID: 0000-0001-9473-9401 Prof. Dr. Hilmi Zengin, Karadeniz Teknik Üniversitesi İIBF, zengin@ktu.edu.tr, ORCID: 0000-0001-9473-9401 


\section{Giriş}

Kamu harcamaları literatürde ilk olarak Adolph Wagner (1883) tarafından ele alınmıştır. Wagner, kamu harcamalarındaki değişikliği gayri safi yurt içi hasıla (GSYİH) ile ilişkilendirerek açıklamaktadır. Bu durumda, kamu harcamaları gayri safi yurt içi hasılanın bir fonksiyonudur. Peacock ve Wiseman (1967), kamu harcamalarının sürekli değil savaş, afet gibi olağan üstü durumlarda artığını ifade etmektedir. Cameron (1978) ise, çalışmasıyla kamu harcamalarına yeni bir bakış getirmiştir.

İkinci dünya savaşından sonra yaşanan otuz yıllık süreçte kapitalist ekonomilerin kamu içerisindeki rolünün büyük ölçüde arttığı ifade edilmektedir. Bunun yanı sıra refah devleti anlayışının gelişmesi ile birlikte devletlerin işsiz, hasta, yaşlı ve az gelirli bireyler için olan gelir transferlerinin arttığ nun yanı sıra, devlet mallarının üretimi ve birçok Avrupa ülkesinde kamuya ait şirketler önemli hale gelmiştir. Çeşitli para ve maliye politikaları kullanılarak işsizlik ve enflasyon oranındaki dalgalanmalar azaltılmaya çalışılmıştır (Cameron, 1978, s.1243). Kamu ekonomisinde yaşanan bu genişleme Cameron (1978, s.1245) tarafindan ekonomik, mali, politik, kurumsal ve uluslararası fonksiyonlarda yaşanan gelişmelerle ilişkilendirerek açıklanmaktadır.

İkinci dünya savaşından sonra artan küreselleşme hareketleri, ilk olarak gelişmiş ülkeler arasında gerçekleşen dış ticaret faaliyetleriyle ortaya çıkmıştır. Ancak özellikle son otuz yılda gelişmekte olan ülkelerde dış ticaret faaliyetleri, ekonomide önemli bir role sahip olmuştur. Gelişmekte olan ülkelerin küreselleşen dünyaya entegre olma amaciyla artan ekonomik faaliyetleri, dış risklerin artmasına ve bazı kesimlerin refah kaybı yaşamasına neden olabilmektedir. Bu durumda devletin, kamu harcamalarını arttırarak, dış risklerin azaltılması ve refah kaybını önleyerek kamu kesimini telafi edici rol üstlenmesine neden olmaktadir.

Küreselleşme hareketleriyle birlikte artan dışa açılmanın kamu harcamalarını pozitif etkilemesi telafi hipotezi olarak adlandırılmaktadır. Bu alanda Cameron (1978)'den sonra en kapsamlı çalışma Rodrik (1998) tarafından gerçekleştirilmiştir. Rodrik (1998, s.998)'e göre, kamu kesimi ile dış ticaret arasında pozitif ilişki olması şaşırtıcı değildir. Bunun nedeni ise, kamu harcamalarının dış şoklara karşı sosyal sigorta sağlamak için kullanılmasıdır. Kamu harcamalarının dış ticaretten kaynaklanan riski azaltıcı etkisinin, sosyal harcamalara kalemi içerisinde yer alan sosyal güvenlik ve refah harcamalarında ve gelir transferleriyle gerçekleşmesi beklenir.

Telafi hipotezinin ortaya çıkış gerekçeleri, ekonomik güvensizlik ve finansal piyasalarda yaşanan dalgalanmaların yanı sıra gelir dağılımında yaşanan eşitsizliktir. Bu durumda bireyler ve üreticiler dolaylı olarak yaşadıkları kayıpları ve gelecekte karşı karşıya kalabilecekleri riskleri devletin telafi etmesini beklemektedirler. Bu nedenle telafi hipotezi, küreselleşmeden kaynaklanan kamu harcamalarının etkisini siyasi birimlerin talep yönlü karar alma mekanizmasıyla açıklamaktadır (Altay ve Aysu, 2013, s.133).

Telafi hipotezinin aksine etkinlik hipotezi, dış ticaret faaliyetlerinin kamu harcamalarını olumsuz etkilediği görüşüne dayanmaktadır. Etkinlik hipotezine göre, vergi rekabetiyle ilgili olarak ileri sürülen hareketlilik, vergi gelirleri üzerinde aşağı yönlü bir baskı oluşturarak kamu harcamalarında bir azalamaya neden olabilmektedir. Bunun nedeni, vergi gelirleri ve borçlanma yoluyla bütçesi oluşturulan kamu harcamalarının ülkelerin dışa açılması neticesinde arttırmasıyla kişilerin ve firmaların yatırım kararlarının olumsuz etkilenebilmesidir. Literatürde bu olguya dışlama etkisi (crowding out) denmektedir.

Uluslararası ticaretin, ücret ve istihdam üzerinde olumsuz etkilerinin olabileceği bazı ekonomistler tarafından ileri sürülmektedir. Bu durumun nedeni olarak, işgücünün belirli kesimlerinin, özellikle de düşük gelirli ve/veya düşük vasıflların, uluslararası ticaretten olumsuz etkilenmesi gösterilmektedir (Balle ve Vaidya, 2002, s.289). Rodrik (1998), dişa açıklık yoluyla maruz kalınan riskin kamu harcamaları tarafından telafi edilebileceğini öne sürmektedir. Ancak ticari açıklığın artması, vergi faktörlerinin hareketliliğine neden olabilir. Dolayısıyla, telafi hipotezinin ve etkinlik hipotezinin net etkisi, oldukça belirsizdir (Liberati, 2007, s.216-217). Özetle telafi hipotezi, dışa açıklığın kamu harcamaları üzerindeki etkisini talep yönlü incelerken; etkinlik hipotezi bu etkiyi arz yönlü incelemektedir. Dış ticaret hareketlerinin kamu harcamalarında artışa neden olması, vergi oranlarında artış yaşanması yoluyla elde ettiği gelirlerde de artış 
yaşanmasına neden olacaktır. Bu durum yerli üreticinin uluslararası ticarette rekabet edebilirliğini azaltmaktadır (Altay ve Aysu, 2013, s.133).

Kamu harcamaları ve dışa açıklık arasındaki ilişkiyi dikkate alan telafi ve etkinlik hipotezlerini 1987-2015 dönemi için panel eşbütünleşme testi yardımıyla inceleyen bu çalışma, dört bölümden oluşmaktadır. Giriş bölümünün ardından literatür araştırmasına ikinci bölümde yer verilirken, üçüncü bölümde veri seti ve yöntem belirtilmiş ve ampirik bulgular dördüncü bölümde özetlenmiştir. Sonuç bölümünde ise, konu özetlenerek elde edilen bulgular yorumlanmıştır.

\section{Literatür Taraması}

Ülkelerin artan dış ticaret faaliyetleri birçok riski beraberinde getirmektedir. Karşılaşılan risklerin minimize edilmesinde ise, devletin telafi edici rol üstlenmesi beklenmektedir. Cameron (1978) ile başlayan kamu harcamaları ile dışa açıklık arasındaki ilişkinin incelemesi ilk olarak 1960-1975 dönemini ve OECD ülkelerini ele alarak gerçekleştirilmiştir. Rodrik (1998) tarafindan kapsamlı bir şekilde ele alınan bu ilişkide, dış ticarette yaşanan artışın kamu harcamalarını arttırdığı sonucuna ulaşılmıştır. Literatürde yer alan çalışmalar, tablo 1'de özetlenmektedir. Kamu harcamaları ve dışa açıklık arasındaki ilişkiyi sınayan çalışmalardan Molana vd. (2004), Jeanneney ve Hua (2004), Kimakova (2009), Gadea vd (2009), Shahbaz vd (2010), Saenz vd (2013), Zeren ve Ergün (2013), Genç ve Telatar (2015), Taşar (2016) ve Tuncer (2016), ele alınan ülkelerde telafi hipotezinin geçerli olduğunu tespit etmişlerdir. Balle ve Vaida (2002), Liberati (2007), Benarroch ve Pandey (2008),
Ram (2009) ve Altay ve Aysu (2013)'nun elde ettikleri bulgura göre ise, söz konusu ülkelerde etkinlik hipotezi geçerlidir; mevcut ilişki negatif yönlüdür ve küreselleşme kamu harcamalarını azaltmaktadır. Bunun yanı sıra, Reis-Mourão (2007), Dreher vd. (2008), Aydoğuş ve Topçu (2013), Jettera ve Parmeter (2014) ve Sener vd. (2015)'in elde ettikleri bulgulara göre, değişkenler arasında ilişki bulunamamıştır. Gammer vd. (2008) ise, küreselleşmenin kamu büyüklügünü etkilemediğini, fakat yabancı doğrudan yatırımların sosyal harcamalara doğru kayarak telafi hipotezini desteklediği sonucuna ulaşmıştır.

Ayrıca, 119 ülkeyi düşük ve yüksek gelir grubuna ayırarak 1972-2000 dönemini Sabit etkili panel veri analiziyle inceleyen Benarroch ve Pandey (2012), değişkenler arasında ilişki olmadığını ancak yüksek gelire sahip ülkelerde negatif ilişki olduğunu ve düşük gelir grubundaki ülkelerin dişa açıklı̆̆ının eğitim harcamalarını etkileyebileceğini; 24 geçiş ekonomisi kapsamında 1990-2011 dönemi için Pedroni Eşbütünleşme ve Kao ve Johansen eşbütünleşme testlerini kullanarak inceleyen Zortuk ve Beşer (2014), demokratik yapısı güçlü geçiş ekonomilerinin telafi hipotezini kısmen desteklerken, Bosna Hersek, Ukrayna, Gürcistan ve Moldova’da kamu büyüklügünün ticari açıklıktaki değişmelerden bağımsız olarak dış risk ile pozitif ilişkili olduğunu tespit etmişlerdir.

Literatür incelendiğinde MINT ülkeleri; Meksika, Endonezya, Nijerya ve Türkiye’yi ele alan çalışmaya rastlanmamıştır. Ayrıca, bu ülkeler için çok kırılmalı panel eşbütünleşme testi uygulanarak literatüre katkı sağlanması amaçlanmaktadır 
Tablo 1. Literatür Özeti

\begin{tabular}{|c|c|c|c|}
\hline Yazar & Dönem & Yöntem & Sonuç \\
\hline $\begin{array}{l}\text { Balle ve Vaidya } \\
(2002)\end{array}$ & 1987-1998 / Amerika & Regresyon Yöntemi & $\mathrm{TD} \rightarrow \mathrm{GS}^{-}$ \\
\hline $\begin{array}{l}\text { Molana vd. } \\
(2004)\end{array}$ & 1948-1998 / 23 OECD ülkesi & Sims, Granger Nedensellik & $\mathrm{TD} \rightarrow \mathrm{GS}^{+}$ \\
\hline $\begin{array}{l}\text { Jeanneney ve Hua } \\
\text { (2004) }\end{array}$ & 1996-1998 / Çin & Korelasyon Analizi & $\mathrm{TD} \leftrightarrow \mathrm{GS}^{+}$ \\
\hline Liberati (2007) & $\begin{array}{l}\text { 1965-1975, 1975-1985 ve 1995-2005/ } \\
\text { Avrupa ülkeleri ve Amerika, Kanada, } \\
\text { Avusturalya, Yeni Zellanda ve } \\
\text { Japonya }\end{array}$ & $\begin{array}{l}\text { Havuzlanmış Panel Veri } \\
\text { Sabit Etkili Panel Veri }\end{array}$ & $\mathrm{TD} \rightarrow \mathrm{GS}^{-}$ \\
\hline $\begin{array}{l}\text { Reis-Mourão } \\
(2007)\end{array}$ & 1942-2002 / Pakistan & $\begin{array}{l}\text { EG Eşbütünleşme } \\
\text { Hata Düzeltme Modeli }\end{array}$ & $\mathrm{TD} \neq \mathrm{GS}$ \\
\hline $\begin{array}{l}\text { Benarroch ve } \\
\text { Pandey (2008) }\end{array}$ & 1970-2000 / 96 ülke & $\begin{array}{l}\text { Panel Granger Nedensellik } \\
\text { Sabit Etkiler Modeli }\end{array}$ & $\begin{array}{l}\mathrm{TD} \mathrm{GS}^{-, \mathrm{b}} \\
\mathrm{TD} \neq \mathrm{SSE} \\
\mathrm{TD} \rightarrow \mathrm{ES}^{\mathrm{a}}\end{array}$ \\
\hline Dreher vd. (2008) & $\begin{array}{l}\text { 1971-2001 / } 60 \text { ülke } \\
\text { 1990-2001 / OECD ülkeleri }\end{array}$ & $\begin{array}{l}\text { Korelasyon Analizi, } \\
\text { SUR Yöntemi }\end{array}$ & $\mathrm{TD} \neq \mathrm{GS}$ \\
\hline $\begin{array}{l}\text { Gemmel vd. } \\
(2008)\end{array}$ & 1980-1997 / 25 OECD ülke & Sabit Etkiler Modeli & $\begin{array}{l}\mathrm{TD} \neq \mathrm{GS} \\
\mathrm{FDI} \rightarrow \mathrm{SS}\end{array}$ \\
\hline Kimakova (2009) & 1980-2003 / 87 ülke & $\begin{array}{l}\text { Rassal Etkiler Modeli } \\
\text { Sabit Etkiler Modeli }\end{array}$ & $\mathrm{TD} \rightarrow \mathrm{GS}^{+}$ \\
\hline Ram (2009) & 1960-2000 / 150 ülke & Havuzlanmış Panel Veri & $\mathrm{TD} \leftrightarrow \mathrm{GS}^{-}$ \\
\hline Gadea vd (2009) & 1960-2000 / İspanya & JJ Eşbütünleşme & $\mathrm{TD} \rightarrow \mathrm{GS}$ \\
\hline $\begin{array}{l}\text { Shahbaz vd } \\
(2010)\end{array}$ & 1971-2006 / Pakistan & $\begin{array}{l}\text { JJ Eşbütünleşme } \\
\text { FMOLS Yaklaşımı }\end{array}$ & $\mathrm{TD} \rightarrow \mathrm{GS}^{+}$ \\
\hline $\begin{array}{l}\text { Altay ve Aysu } \\
(2013)\end{array}$ & 1974-2010 / 17 Avrupa ülkesi & $\begin{array}{l}\text { Pedroni Eşbütünleşme, } \\
\text { Panel DOLS Tahmincisi }\end{array}$ & $\begin{array}{l}\mathrm{TD} \rightarrow \mathrm{GS}^{-} \\
\mathrm{FDI} \rightarrow \mathrm{GS}^{-}\end{array}$ \\
\hline $\begin{array}{l}\text { Aydoğuş ve } \\
\text { Topçu (2013) }\end{array}$ & 1974-2011 / Türkiye & EG Eşbütünleşme & $\mathrm{TD} \neq \mathrm{GS}$ \\
\hline Saenz vd (2013) & 1960-2000 / İspanya & JJ Eşbütünleşme & $\mathrm{TD} \rightarrow \mathrm{GS}$ \\
\hline $\begin{array}{l}\text { Zeren ve Ergün } \\
\text { (2013) }\end{array}$ & 1970-2011 / 15 Avrupa ülkesi & EK Panel Nedensellik & $\mathrm{TD} \rightarrow \mathrm{GS}$ \\
\hline $\begin{array}{l}\text { Aregbeyen ve } \\
\text { Ibrahim (2014) }\end{array}$ & 1970-2012 / Nijerya & ARDL Sinır Testi & $\mathrm{GS} \rightarrow \mathrm{TD}$ \\
\hline $\begin{array}{l}\text { Jettera ve } \\
\text { Parmeter (2015) }\end{array}$ & 1960-2000 / 154 ülke & $\begin{array}{l}\text { Havuzlanmış Panel Veri } \\
\text { İki kuyruklu Sabit Panel Veri }\end{array}$ & $\mathrm{TD} \neq \mathrm{GS}$ \\
\hline $\begin{array}{l}\text { Genç ve Telatar } \\
(2015)\end{array}$ & 1980-2013 / Türkiye & $\begin{array}{l}\text { EG Eşbütünleşme, } \\
\text { Hata Düzeltme Modeli }\end{array}$ & $\mathrm{TD} \rightarrow \mathrm{GS}$ \\
\hline Sener vd. (2015) & 1975-2013 / Türkiye & $\begin{array}{l}\text { JJ Eşbütünleşme, } \\
\text { Granger Nedensellik }\end{array}$ & $\mathrm{TD} \neq \mathrm{GS}$ \\
\hline Taşar (2016) & 1961-2014 / Türkiye & ARDL Sınır Testi & $\mathrm{TD} \rightarrow \mathrm{GS}+$ \\
\hline Tuncer (2016) & 2004-2011 / Türkiye'deki 26 alt bölge & $\begin{array}{l}\text { Pedroni,Kao Eşbütünleşme, } \\
\text { Panel DOLS Tahmincisi }\end{array}$ & $\begin{array}{l}\mathrm{TD} \rightarrow \mathrm{SS}^{+} \\
\mathrm{TD} \rightarrow \mathrm{SSE}^{+}\end{array}$ \\
\hline
\end{tabular}

Not: SS, sosyal harcamalar; SSE, sosyal güvelik harcamaları; ES; eğitim harcamaları; FDI, yabacı doğrudan yatırımlar; GS, kamu harcamaları; EG, Engle-Granger; JJ, Johansen-Juselius; a,b sırasıyla düşük ve yüksek gelirli ülkeleri ifade etmektedir. 


\section{Veri Seti ve Yöntem}

Gelişen ekonomiler arasında sayılan MINT ülkeleri için dışa açılmanın kamu harcamaları üzerindeki etkisini telafi ve etkinlik hipotezini dikkate alarak inceleyen bu çalışmada, 1987-2015 dönemi kullanılmıştır. Dışa açıklık değişkeni (TD) ithalat ve ihracat toplamının GSYİH içerisindeki payı ve kamu harcamaları (GS), nihai kamu tüketim harcamaları olarak Dünya Bankasından temin edilmiştir. Kamu harcamaları verisi logaritmik olarak analizlere dahil edilmiştir.

Ülkelere ait kamu harcamaları Şekil l'de yer alan MGS; Meksika'nın kamu harcamalar1nın, IGS; Endonezyảnın kamu harcamalarının, NGS; Nijeryảnın kamu harcamalarının, TGS ise Türkiye’nin kamu harcamalarının logaritmik dönüşümlerini ifade etmektedir. Şekil 1 incelendiğinde, kamu harcamaları Nijerya hariç diğer ülkelerde birbirlerine yakın seyretmekte ve dönemler itibariyle belirgin bir değişikliğe uğramamaktadır. Petrol İhraç Eden Ülkeler Örgütü (OPEC) üyesi olan Nijerya ekonomisinde, 2003 yılında yaşanan değiş̧iklikten sonra serinin eğimi değişmektedir. 2003 yllında ülkede artmaya başlayan terör faaliyetlerinin yanı sıra, petrol güzergahlarının alt yapı ve inşaat çalışmaları için aktarılan ödenekler kamu harcamalarında önemli bir artı̧̧ yaşanmasına neden olmuştur.

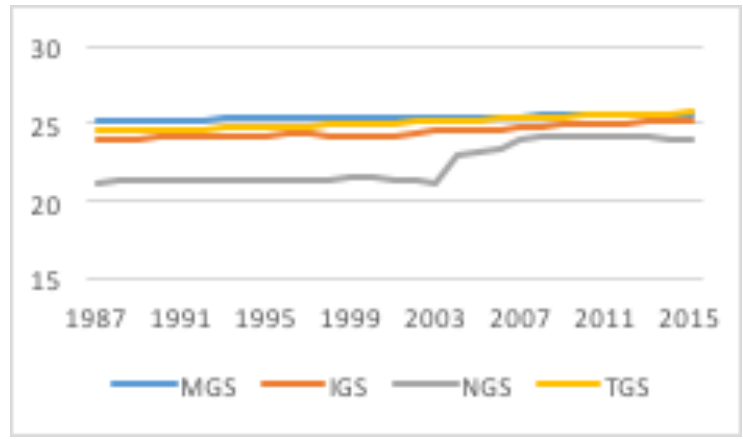

Şekil 1. MINT ülkelerinin Kamu Harcamaları

Panel veri analizleri zaman ve kesit boyutlarından meydana geldiği için bir ülkede meydana gelen şokun diğer ülkelerde bir etki meydana getirmesi küreselleşen ekonomik faaliyetlerde beklenmektedir. Bu durumun istatistiksel olarak analiz edilmesi amaciyla serilerin yatay kesit bağımlılığına sahip olmadığını ifade
MINT ülkelerinin dışa açıklık değerlerini ifade eden Şekil 2'de, MTD; Meksikảnın dışa açılklı̆ını, ITD; Endonezyảnın dışa açıklığını, NTD; Nijeryảnın dışa açıklığını, TTD ise Türkiye’nin dışa açıklığını göstermektedir. Meksika’nın ihracat ve ithalat faaliyetlerinin önemli bir kısmını coğrafi konumu etkisiyle gelişmiş ülkelerle gerçekleştirmesi, dışa açıklığının genel olarak yıllar itibariyle artı̧̧ göstermesine neden olmaktadır. Endonezya, 1997 yılında Doğu Asya bölgesinde yaşanan krizden etkilenmiş ve 1998 yllında siyasi gerginlikler meydana gelmiştir. Bu durum milli gelirde düşüş yaşanmasına neden olmuştur. İhracat ve ithalatın milli gelire oranını ifade eden dışa açılık değerinde payda meydana gelen azalıs değerde artış yaşanması ile sonuçlanmaktadır. Nijerya genel olarak dış ticaret fazlası veren bir ülke olmasına rağmen, özellikle 2011 yılından sonra ithalatında önemli azalışlar meydana gelmiştir. Aynı zamanda 2008 petrol rafinelerine yapılan saldırı petrol ihracatının azalmasına neden olmuştur. Türkiye'nin dışa açıklığı ise, 1997-1998 Doğu Asya krizinden etkilenmiştir. Bu dönemler haricinde ise, seride genel olarak bir değişme görülmemektedir.

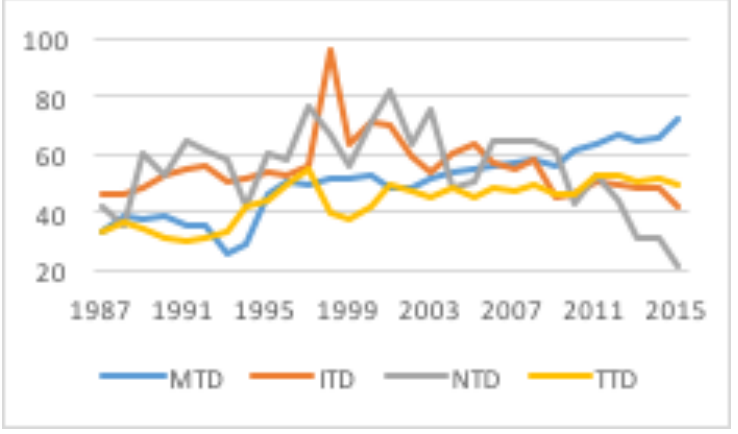

Şekil 2. MINT ülkelerinin Dışa açıklığı

eden $\mathrm{H}_{\mathrm{o}}$ hipotezi test edilmektedir. Bu amaçla literatüre ilk katkıyı Lagrange çarpan (LM) testi ile yapan Breusch ve Pagan (1980) tarafindan önerilen model, denklem 1 yardımıyla gösterilmektedir. Denklemde, $\hat{\rho}_{i j}$ her bir kesit için hesaplanan hata terimleri korelasyon katsayısını ifade eder. 


$$
\mathrm{CD}_{\mathrm{LM} 1}=\mathrm{T} \sum_{i=1}^{N-1} \sum_{j=i+1}^{N} \hat{\rho}_{\mathrm{ij}}^{2}
$$

Breusch ve Pagan (1980)'nın geliştirdiği yatay kesit bağımlılığ 1 testi ile Pesaran (2004)'nın geliştirdiği yatay kesit bağımlılığı testi Monte Carlo çalışmaları ile karşılaştırıldığında, küçük örneklerde serilerin birim kök içermesi veya kırılmaya sahip olması durumunda Pesaran (2004)'nın testinin daha güçlü sonuçlar verdiği gözlenmiștir (Pesaran, 2004, s.1). N ve T geniş olduğunda da yatay kesit bağımlılığının olmadığını ileri süren sıfır hipotezini test etmek için denklem 2 ile ifade edilen $\mathrm{CD}_{\mathrm{LM} 2}$ kullanılabilmektedir.

$$
\mathrm{CD}_{\mathrm{LM} 2}=\sqrt{\frac{1}{\mathrm{~N}(\mathrm{~N}-1)} \sum_{\mathrm{i}=1}^{\mathrm{N}-1} \sum_{\mathrm{j}=\mathrm{i}+1}^{\mathrm{N}}\left(\mathrm{T} \hat{\rho}_{\mathrm{ij}}^{2}-1\right)}
$$

$\mathrm{CD}_{\mathrm{LM} 2}$ testinde $\mathrm{N}$ geniş olduğu durumda bozulmalar meydana gelmektedir. Pesaran (2004) aynı çalışmada, N geniş olduğu durumda yatay kesit bağımlılığını test etmek amacıyla ağırlıklandırma matrisini küçük örnekler için kullanıma uygun hale getirmiştir (Pesaran, 2004, s.5).

$$
\mathrm{CD}_{\mathrm{LM} 3}=\sqrt{\frac{2 \mathrm{~T}}{\mathrm{~N}(\mathrm{~N}-1)}\left(\sum_{\mathrm{i}=1}^{\mathrm{N}-1} \sum_{\mathrm{j}=\mathrm{i}+1}^{\mathrm{N}}\left(\hat{\rho}_{\mathrm{ij}}\right)\right)}
$$

Pesaran vd (2008), Pesaran (2004) CD testinin tutarsız sonuçlar verdiği durumlarda daha tutarlı sonuçlar veren yeni bir test önermektedirler. Bu test, $\mathrm{T} \rightarrow \infty$ sonra $\mathrm{N} \rightarrow \infty$ olduğunda tutarlı sonuçlar vermektedir. Düzeltilmiş $\mathrm{CD}_{\mathrm{LM} 4}$ test istatistiği denklem 4 yardımıyla ifade edilmektedir:

$\mathrm{CD}_{\mathrm{LM} 4}=\sqrt{\frac{2}{\mathrm{~N}(\mathrm{~N}-1)}} \sum_{\mathrm{i}=1}^{\mathrm{N}-1} \sum_{\mathrm{j}=\mathrm{i}+1}^{\mathrm{N}} \frac{(\mathrm{T}-\mathrm{k}) \hat{\rho}_{\mathrm{ij}}^{2}-\mu_{\mathrm{Tij}}}{\sqrt{v_{T i j}^{2}}}$

Panel veri analizlerinde yatay kesit bağımlılığının yanı sıra, eğim katsayısının homojen olduğunu iddia eden $\mathrm{H}_{\mathrm{o}}$ hipotezi, heterojenliği kabul eden karşıt hipoteziyle sınanmaktadır. Pesaran ve Yagamata (2008)'nın çalışmalarında homojenlik testi için önerdiği istatistikler ( $\widetilde{\Delta}$ ve $\widetilde{\Delta}_{\text {adj }}$ testleri), Swamy (1970)'nin çalışmasına dayanmaktadır. Monte Carlo sonuçları, T ve N’nin farklılık gösterdiği durumlarda $\tilde{\Delta}_{\text {adj }}$ testinin boyut ve güç özelliklerinin daha güçlü sonuçlar verdiğini göstermektedir (Pesaran ve Yamagata, 2008, s.50-57).

$$
\begin{aligned}
& \tilde{\Delta}=\sqrt{N}\left(\frac{N^{-1} \tilde{S}-k}{\sqrt{2 k}}\right), \\
& \tilde{\Delta}_{a d j}=\sqrt{N}\left(\frac{N^{-1} \tilde{S}-E\left(\tilde{z}_{i T}\right)}{\sqrt{\operatorname{Var}\left(\tilde{z}_{i T}\right)}}\right)
\end{aligned}
$$

Çalışmada ayrıca ikinci nesil birim kök testleri olarak adlandırılan yatay kesit bağımlılığı dikkate alan CADF ve PANIC birim kök testleri kullanılmıştır. CADF birim kök testi, Pesaran (2006) tarafından Im, Pesaran ve Shin (2003) (IPS) çalışmasının yatay kesit bağımlılı̆̆ını dikkate alınmasıyla geliştirilmiştir. Temel olarak, her bir kesit için ADF istatistiğini hesaplayarak kesitler için birim kökün varlığını tespit etmektedir. Aynı zamanda elde edilen CADF birim kök testlerinin aritmetik ortalamasını alarak, panel için birim kökün varlığını CIPS istatistiği yardımıyla belirlenmektedir ve $\mathrm{N}>\mathrm{T}$ ve $\mathrm{T}>\mathrm{N}$ olduğu durumlarda tutarlı sonuçlar vermektedir. Elde edilen sonuçlar, Pesaran (2006) çalışmasında yer alan tablo kritik değerleri ile karşılaştırılmaktadır.

Serilerin durağanlık ve kendine ait özelliklerini belirlemede kullanılan PANIC (Panel Analysis of Nonstationarity in Idiosyncratic and Common Components) birim kök testi, Bai ve $\mathrm{Ng}$ (2004) tarafından geliştirilmiştir. Bai ve $\mathrm{Ng}$ (2004)'nin çalışması, ADF birim kök testini panel veriler için uygulayan Maddala ve $\mathrm{Wu}$ (1999)'nun çalışmasına dayanmaktadır. Bu çalışmada, Choi (2001) ve Maddala ve Wu (1999)'nun çalışmaları $\mathrm{N} \rightarrow \infty$ için geliştirilmiştir. Bu test ortak faktör yapısını dikkate alarak, yatay kesit bağımlılığı altında değişenlerin birim köke sahip olduğunu araştırmaktadır. Aynı zamanda heterojenliğe izin veren bu test, dengesiz panel verileri için de kullanılabilir.

Westerlund (2006), panel regresyonun deterministik bileşenlerinde yapısal değişikliğe uyum sağlayan eşbütünleşmenin olduğunu belirten sıfır hipotezini, eşbütünleşme ilişkisinin olmadığını ifade eden alternatif hipotezine karşı sınanmasını önermektedir. McCoskey ve Kao (1998)'nun geliştirdiği LM testine dayanan bu test yatay kesit bağımlılığı dikkate almakta ve $\mathrm{T} \rightarrow \infty$ sonra $\mathrm{N} \rightarrow \infty$ iken, standart normal dağıllma yaklaşmaktadır. Bunun yanı sıra, her bir kesit için 
kırılmanın olmadığ durum ve sabitli ve/veya trendli modelde kırılmanın olduğu durum için analiz yapabilmektedir ve her bir kesit için kırılma tarihlerini belirleyebilmektedir. Monte Carlo analizi sonuçları, testin küçük ve büyük örnekler için de etkin sonuçlar verdiğini göstermektedir.

Westerlund (2006) tarafından geliştirilen eşbütünleşme testi, denklem 6,7,8 yardımıyla uygulanmaktadır (Narayan ve Smyth, 2008, s.2336).

$\mathrm{HCE}=\vartheta_{\mathrm{ij}}+\delta_{\mathrm{it}} \mathrm{Y}_{\mathrm{it}}+\mathrm{e}_{\mathrm{it}}$

$\mathrm{e}_{\mathrm{it}}=\mathrm{r}_{\mathrm{it}}+\mathrm{u}_{\mathrm{it}}$

$\mathrm{r}_{\mathrm{it}}=\mathrm{r}_{\mathrm{it}-1}+\varphi_{\mathrm{i}} \mathrm{u}_{\mathrm{it}}$

$j=1, \ldots, M_{i}+1$ yapısal kırılma sayısını ifade etmektedir. Bu test $\mathrm{T}_{\mathrm{i} 1}, \ldots . ., \mathrm{T}_{\mathrm{iN}}$ tarihleri için maksimum $\mathrm{M}_{\mathrm{i}}$ kırılma veya $M_{i}+1$ rejim kırılmasına izin vermektedir.

Eşbütünleşme ilişkisine sahip olan fonksiyon için her bir ülkeye ilişkin katsayı hesaplanmasına olanak veren CCE (Common Correlated Effects) katsayı tahmincisi kullanılmıștır. Pesaran (2006) tarafından geliştirilen ve ortak faktör yapısını kullanan bu tahminci, yatay kesit bağımlılığı altında homojen ve heterojen modellerde kullanılabilmektedir. Tahminci, $\mathrm{T}<\mathrm{N}, \mathrm{T}>\mathrm{N}$ ve ya $\mathrm{T}$ ve $\mathrm{N}$ nin sabit olduğu durumlarda da tutarlı sonuç vermektedir.

CCE tahmincileri, CCEMG (Common Correlated Effects Mean Group) ve CCEP (Common Correlated
Effects Pooled) olmak üzere iki farklı tahmin gerçekleştirilmesine imkan vermektedir. CCEMG tahmincisi, kesitlerin CCE tahminleri $\hat{b}_{i}$ lerin basit ortalamasından oluşmaktadır (Pesaran, 2006, s.982).

$$
\hat{b}_{C C E M G}=N^{-1} \sum_{i=1}^{N} \hat{b}_{i}
$$

CCEP tahmincisini gösteren denklem $\mathrm{d}$ de ise, $\theta$ 1/N e eşit olan ağırlıklandırmayı ifade etmektedir. $\theta_{i}=\sigma_{i}^{-2} / \sum_{i=1}^{N} \sigma_{i}^{-2}$ denkleminden elde edilmektedir (Pesaran, 2006, s.986).

$\hat{b}_{C C E P}=\left(\sum_{i=1}^{N} \theta_{i} X_{i}^{\prime} \bar{M}_{\omega} X_{i}\right)^{-1}\left(\sum_{i=1}^{N} \theta_{i} X_{i}^{\prime} \bar{M}_{\omega} y_{i}\right)$

\section{Ampirik Sonuçlar}

MINT ülkelerinin kamu harcamaları ve dışa açıklık serilerinde testleri kullanılarak yatay kesit bağımlılığ 1 test edildiğinde $\mathrm{H}_{\mathrm{o}}$ hipotezi reddedilmiştir. Tablo 2 yardımıyla gösterilen sonuçlara göre, seriler yatay kesit bağımlılığına sahiptir. Bu durumda, bir ülkede meydana gelen bir şokun diğer ülkeleri etkilediği söylenebilir. $\mathrm{Bu}$ nedenle serilerde birim kökün varlığı, yatay kesit bağımlılığı dikkate alan CADF ve PANIC panel birim kök testleri yardımıyla araştırılmıştır.

Tablo 2. Yatay Kesit Bağımlılığının Test Edilmesi

\begin{tabular}{|c|c|c|c|c|}
\hline \multirow{2}{*}{ Test stat. } & \multicolumn{2}{|c|}{ Constant } & \multicolumn{2}{c|}{ Constant + Trend } \\
\cline { 2 - 5 } & GS & TD & GS & TD \\
\cline { 2 - 5 } & Statistic & Statistic & Statistic & Statistic \\
\hline $\mathrm{CD}_{\mathrm{LM} 1}$ & $21.03^{*}$ & $24.01^{*}$ & $23.12^{*}$ & $27.63^{*}$ \\
\hline $\mathrm{CD}_{\mathrm{LM} 2}$ & $4.34^{*}$ & $5.19^{*}$ & $4.94^{*}$ & $6.24^{*}$ \\
\hline $\mathrm{CD}_{\mathrm{LM} 3}$ & $-2.99^{*}$ & $-3.59^{*}$ & $-2.95^{*}$ & $-3.52^{*}$ \\
\hline $\mathrm{CD}_{\mathrm{LM} 4}$ & $8.04^{*}$ & $4.57^{*}$ & $7.61^{*}$ & $4.54^{*}$ \\
\hline
\end{tabular}

Not: ", \%1 anlamlılık seviyesini ifade etmektedir. 
Tablo 3'de yer alan CADF birim kök testi sonuçlarına göre, değişkenler serisi sabitli ve trendli modelde $\mathrm{I}(0)$ seviyesinde durağan iken, sabitli modelde I(1) seviyesinde durağandır. Eşbütünleşme testinin uygulanabilmesi için serilerin I(1) seviyesinde durağan olması gerekmektedir. Serilerin sabitli ve sabitli ve trendli modellerinden elde edilen sonuçlar değişiklik gösterdiği için birim kökün varlığ PANIC birim kök testi yardımıyla da araştırılmıştır.

Tablo 3. CADF Birim Kök Testi

\begin{tabular}{|l|c|c|c|c|}
\hline \multirow{2}{*}{ Ülkeler } & \multicolumn{2}{|c|}{$\mathrm{I}(0)$} & \multicolumn{2}{c|}{$\mathrm{I}(1)$} \\
\cline { 2 - 5 } & Sabitli & Sabitli+Trendli & Sabitli & Sabitli+Trendli \\
\hline GS & & & & -2.29 \\
\hline Meksika & -2.87 & -0.86 & -2.23 & -3.04 \\
\hline Endonezya & -2.39 & -2.48 & $-2.98^{* * *}$ & $-3.87^{* *}$ \\
\hline Nijerya & -2.26 & -3.01 & $-3.93^{* *}$ & $-4.87^{* *}$ \\
\hline Türkiye & -1.06 & $-3.95^{* *}$ & $-5.10^{*}$ & $-3.52^{*}$ \\
\hline CIPS İstatistiği & -2.15 & $-2.58^{* * *}$ & $-3.56^{*}$ & \\
\hline TD & & & & - \\
\hline Meksika & 0.03 & $-3.46^{* *}$ & $-3.83^{* *}$ & - \\
\hline Endonezya & -2.20 & $-3.77^{* *}$ & $-4.32^{*}$ & - \\
\hline Nijerya & -0.21 & -2.46 & $-3.85^{* *}$ & - \\
\hline Türkiye & -1.44 & $-3.29^{* * *}$ & $-3.58^{* *}$ & - \\
\hline CIPS İstatistiği & -0.96 & $-3.24^{*}$ & $-3.89^{*}$ & \\
\hline
\end{tabular}

Not: Maksimum gecikme uzunluğu 3 olarak alınmıș ve optimal gecikme uzunlukları, SCI göre belirlenmiştir. *, \%1 anlamlılık seviyesini ifade etmektedir. CADF istatistiği kritik değerleri, sabitli modelde Pesaran (2007, s.275), sabit ve trendli modelde Pesaran (2007, s.276); CIPS istatistiği kritik değerleri, sabitli modelde Pesaran (2007, s.280) ve sabit ve trendli modelde Pesaran (2007, s.281) çalışmasında elde edilmektedir.

PANIC birim kök testinin sonuçları tablo 4 de gösterilmektedir. Elde edilen bulgulara göre, her iki seri, sabitli ve sabitli ve trendli modellerinde birinci farkında (I(1)) durağandır. Sonuç olarak, ele alınan değișkenlerin I(1) seviyesinde durağan olduğu belirlenmiștir.

Tablo 4. PANIC Birim Kök Testi Sonuçları

\begin{tabular}{|c|l|c|c|c|c|}
\hline \multirow{2}{*}{ Değişkenler } & Test & \multicolumn{2}{|c|}{$\mathrm{I}(0)$} & \multicolumn{2}{|c|}{$\mathrm{I}(1)$} \\
\cline { 2 - 6 } & İstatistiği & Sabitli & Sabit+Trendli & Sabitli & Sabit+Trendli \\
\hline \multirow{2}{*}{ GS } & $Z_{\hat{e}}^{c}$ & -0.77 & -0.32 & $4.45^{*}$ & $3.83^{*}$ \\
\cline { 2 - 6 } & $P_{\hat{e}}^{c}$ & 4.90 & 6.74 & $25.81^{*}$ & $23.32^{*}$ \\
\hline \multirow{2}{*}{ TD } & $Z_{\hat{e}}^{c}$ & -0.78 & 0.27 & $6.00^{*}$ & $6.00^{*}$ \\
\cline { 2 - 6 } & $P_{\hat{e}}^{c}$ & 4.88 & 9.05 & $32.00^{*}$ & $32.00^{*}$ \\
\hline
\end{tabular}

Not: $P_{\hat{e}}^{c}$ Maddal ve Wu (1999); $Z_{\hat{e}}^{\text {c }}$ Choi (2001) tarafından önerilen istatistikleri temsil etmektedir. PANIC birim kök için maksimum ortak faktör sayısı 1 olarak, maksimum gecikme uzunluğu 3 olarak alınmıștır. , \%1 anlamlılık seviyesini ifade etmektedir.

Dışa açılmanın kamu harcamaları üzerindeki etkisine $(\mathrm{GS}=\mathrm{f}(\mathrm{TD})$ ), ilişkin yatay kesit bağımlılı̆̆ 1 ve homojenlik testi sonuçları tablo 5'de yer almaktadır. Elde edilen bulgular sonucunda, $\mathrm{H}_{\mathrm{o}}$ hipotezleri reddedilmiş ve $\mathrm{GS}=\mathrm{f}(\mathrm{TD})$ fonksiyonun yatay kesit bağımlılığına sahip, heterojen bir model olduğu belirlenmiştir. 
Böylelikle eşbütünleşme ilişkisini belirlemek için yapısal kırılmalı ve kırılmasız eşbütünleşme testi yapılmasına imkan veren ve yatay kesit bağımlılı̆̆ını dikkate alan Westerlund (2006) panel eşbütünleşme testi kullanılmıștır.

Tablo 5. Yatay Kesit Bağımılığı ve Homojenlik Testi Sonuçları

\begin{tabular}{|c|l|l|}
\hline Test İstatistiği & Statistic & p-value \\
\hline $\mathrm{CD}_{\mathrm{LM} 1}$ & 47.820 & 0.000 \\
\hline $\mathrm{CD}_{\mathrm{LM} 2}$ & 12.072 & 0.000 \\
\hline $\mathrm{CD}_{\mathrm{LM} 3}$ & 6.241 & 0.000 \\
\hline $\mathrm{CD}_{\mathrm{LM} 4}$ & 7.343 & 0.000 \\
\hline$\tilde{\Delta}$ & 7.667 & 0.000 \\
\hline$\tilde{\Delta}_{a d j}$ & 8.082 & 0.000 \\
\hline \multicolumn{3}{|l}{}
\end{tabular}

Panel eşbütünleşme testi sonuçlarına göre, seriler yapısal kırılmalı ve kırılmasız modellerde değişkenler arasında eşbütünleşme ilişkisinin olduğunu ileri süren $\mathrm{H}_{\mathrm{o}}$ hipotezi kabul edilmiştir. Bu durum, yapısal kırılmalar dikkate alındığı ve alınmadığı modellerde $\mathrm{GS}=\mathrm{F}(\mathrm{TD})$ fonksiyonunun eşbütünleşme ilişkisine sahip olduğunu göstermektedir. Böylelikle, kamu harcamaları ve dışa açıklığın uzun dönemde birlikte hareket ettikleri söylenebilir.

\section{Tablo 6. Çok Kırılmalı Panel Eşbütünleşme Testi Sonuçları}

\begin{tabular}{|l|c|c|}
\hline Model & İstatistik & Bootstrap p-değeri \\
\hline Kırılmasız sabitli model & 5.354 & 0.105 \\
\hline Kırılmasız sabitli ve trendli model & 1.840 & 0.274 \\
\hline Sabitte kırılma & 13.373 & 0.403 \\
\hline Sabit ve trendde kırılma & -44.652 & 0.867 \\
\hline
\end{tabular}

Not: Bootstrap olasılık değerleri 10.000 tekrarlı dağılımdan elde edilmiştir. Maksimum kırılma sayısı 3 olarak alınmıștır. Asimptotik olasılık değerleri, standart normal dağılımdan elde edilmiş ve ortak faktör sayısı 1 olarak alınmıştır.

Söz konusu fonksiyon heterojen olduğu için ülkelere ait katsayı tahminlerinin elde edilmesi amaciyla CCE katsayı tahmincisi kullanılmış ve MINT ülkelerinde geçerli olan hipotez belirlenmeye çalışılmıştır. Sabitli ve sabitli ve trendli modeller için ülkelerin kırılma tarihleri incelendiğinde, genel olarak ülkelerin küresel krizlerden etkilediği gözlemlenmiștir. Bu krizlerin özellikleri ve meydana geldiği coğrafi bölge farklılaşmaktadır. Ancak gelişmekte olan ülkelerde 1980’li yllardan itibaren yoğun olarak artamaya başlayan küreselleşme hareketleri, ülkelerin birbirleri ile olan ekonomik faaliyetlerinde artış yaşanmasına neden olmaktadır. Bu durumda, ülkelerde meydana gelen finansal veya ekonomik değişiklikler diğer ülkelerde de etkisinin göstermektedir. Gelişmekte olan ülkelerden oluşan MINT ülkelerinde de yaşanan küresel krizlerin etkilerinin görülmesi literatürde görülen bir sonuçtur.

Tablo 7. Kırılma Tarihleri

\begin{tabular}{|l|c|c|c|c|c|c|}
\hline Ülke & \multicolumn{3}{|c|}{ Sabit kırılma } & \multicolumn{3}{c|}{ Sabit ve trendde kırılma } \\
\hline Meksika & 1992 & 2005 & 2010 & 1992 & 2001 & - \\
\hline Endonezya & 1991 & 2002 & 2007 & 1992 & 1998 & 2008 \\
\hline Nijerya & 2003 & 2008 & - & 1998 & 2003 & 2009 \\
\hline Türkiye & 1997 & 2003 & 2008 & 1995 & 2005 & - \\
\hline
\end{tabular}


Eşbütünleşme ilişkisine sahip ülkelerin dişa açılklı̆̆1nın kamu harcamaları üzerindeki etkisinin anlamlılığı ve işareti CCE katsayı tahmincisi kullanılarak incelenmiştir. Elde edilen bulgulara göre, MINT ülkelerinin katsayı değerleri işaret olarak farklılaşmasına rağmen istatistiksel olarak anlamlıdır. Meksika ve Türkiye için dışa açıklığın kamu harcamalarına pozitif yansıdığını ifade eden telafi hipotezinin geçerli olduğu; Endonezya ve Nijerya için bu etkinin negatif olduğunu ifade eden etkinlik hipotezinin geçerli olduğu sonucuna ulaşılmıştır.

\section{Tablo 8. Eșbütünleșme Tahmincileri}

\begin{tabular}{|l|l|l|}
\hline Ülker & Katsayı Değeri & t istatistiği \\
\hline Meksika & 0.0034821 & $1.62^{* * *}$ \\
\hline Endonezya & -0.0059868 & $-3.98^{*}$ \\
\hline Nijerya & -0.0106205 & $-2.96^{*}$ \\
\hline Türkiye & 0.0064395 & $1.83^{* * *}$ \\
\hline
\end{tabular}

Not: ${ }^{\prime \prime}$ ve , sırasıyla $\% 10$ ve $\% 1$ anlamlllık seviyelerini ifade etmektedir.

\section{Sonuç}

Küreselleşen dünyada, diş ticaret faaliyetleri özellikle gelişmekte olan ülkelerde önemli bir yere sahiptir. Ancak ülkelerin dışa açılması, beraberinde birçok risk getirmektedir. Ülkelerin dışa açıklığının artmasıyla birlikte meydana gelen risklerin ve zararların devlet tarafından karşılanacağını ileri süren telafi hipotezi, söz konusu ilişkinin yönünün pozitif olduğunu ifade etmektedir. Bu ilişkinin yönünün negatif olduğu görüşüne dayanan etkinlik hipotezine göre ise, devlet gelirlerini, vergi ve borçlanma kanalı ile oluşturduğu için dışa açılmadan kaynaklanan kayıpların devlet tarafından telafi edilmesi ülke içinde refah kaybının yaşanmasına neden olmaktadır. Bu çalışmada, dünyanın gelişen ekonomileri arasında sayılan ve coğrafi konum olarak önemli bir yere sahip olan MINT ülkeleri için dışa açılmanın kamu harcamaları üzerindeki etkisi, 1987-2015 dönemi kullanılarak Çok Kırılmalı Panel Eşbütünleşme testi yardımı ile incelenmiştir.

Eşbütünleşme testleri genel olarak değişkenler I(1) seviyesinde durağan olduğunda uygulanmaktadır. $\mathrm{Bu}$ nedenle serilere öncelikle birim kök testleri uygulanmış ve yatay kesit bağımlılı̆̆ 1 dikkate alan CADF ve PANIC birim kök testleri sonucunda değişkenlerin I(1) seviyesinde durağan olduğu belirlenmiştir. Çalışmada kullanılan GS=f(TD) fonksiyonu, yatay kesit bağımlılığına ve heterojen yapıya sahip olduğu için bu özellikleri dikkate alan eşbütünleşme testi kullanılmıştır. Bu test, yapısal kırılmanın olduğu ve olmadığ 1 durumda eşbütünleşme ilişkisinin tespit edilebilmesine imkan vermektedir. Elde edilen sonuçlar, her iki durumda da değişkenlerin eşbütünleşik olduğunu göstermektedir. MINT ülkelerinde telafi ve etkinlik hipotezlerinden hangisinin geçerli olduğuna karar verebilmek için yapılan CCE katsayı tahmincisine göre, Meksika ve Türkiye'de değişkenler arasında pozitif ilişki bulunmuştur; dış ticaret faaliyetlerinden kaynaklanan risk kamu harcamaları ile giderilmektedir ve bu durumda telafi hipotezi geçerlidir. Ancak, Endonezya ve Nijerya için değişkenler arasında negatif ilişki söz konusudur; diş ticaret faaliyetleri kamu harcamalarını olumsuz etkilemektedir ve etkinlik hipotezi geçerlidir. Tablo 9'da yer alan 2015 ihracat ve ithalat rakamları incelendiğinde, elde edilen sonuçlar desteklenmektedir. Ülkelerin diş ticaret faaliyetlerinde kamu kurumları tarafindan desteklenmesi dış ticaret faaliyetlerini olumlu etkilemekte ülkenin ekonomik gelişimine yansımaktadır. Ayrıca yapılan araştırmalar, ülkelerin dış ticaret faaliyetlerinin artmasının turizm vb. diğer ekonomik faaliyetlerine de olumlu yansıdığını göstermektedir.

Tablo 9. MINT Ülkelerinin Ithalat ve İhracat Dünya Sıralamaları

\begin{tabular}{|l|l|l|l|l|}
\hline \multirow{2}{*}{ Ülkeler } & \multicolumn{2}{|l|}{ Mal Ticareti } & \multicolumn{2}{l|}{ Ticari Hizmetler } \\
\cline { 2 - 5 } & İhracat & Ithalat & İhracat & Ithalat \\
\hline Meksika & 13 & 12 & 39 & 33 \\
\hline Endonezya & 30 & 30 & 41 & 32 \\
\hline Nijerya & 50 & 51 & 96 & 41 \\
\hline Türkiye & 31 & 21 & 26 & 39 \\
\hline
\end{tabular}

Kaynak: Dünya Ticaret Örgütü 


\section{Kaynakça}

Altan, A. ve Aysu, A. (2013). Etkinlik ve Telafi Edici Etki Hipotezi: Seçilmiş Ülkeler Üzerine Ampirik Bir İnceleme. TİSK Akademi, 1, 130-154.

url'si.http://eds.a.ebscohost.com/eds/pdfviewer/ pdfviewer?vid $=3 \&$ sid $=b 1746 d 2 f-9 c 4 c-498 a-a 9 a 5-$ 9cc7731837a8\%40sessionmgr4006, Erişim Tarihi 27 Ekim 2017

Aregbeyen, O., Ibrahim, T. M. (2014). Trade Openness-Government Size Nexus: Compensation Hypothesis Considered for Nigeria. Journal of Reviews on Global Economics, 3, 364-372. urls'si. http://lifescienceglobal.com/pms/index.php/jrge/ article/view/2417, Erişim Tarihi 26 Temmuz 2017

Aydogus, I., Topcu, M. (2013). An Investigation of CoIntegration and Causality between Trade Openness and Government Size in Turkey. International Journal of Economics and Financial Issues, 3(2), 319-323. urls'si. http://www.econjournals.com/index.php/ijefi/article/viewFile/406/pdf, Erişim Tarihi 26 Temmuz 2017

Bai, J., Ng, S. (2004). A Panic Attack on Unit Roots and Cointegration. Econometrica, 72 (4), 1127-1177. doi: 10.1111/j.1468-0262.2004.00528.x

Balle, F., Vaidya, A. (2002). A Regional Analysis of Openness and Government Size. Applied Economics Letters, 9 (5), 289-292. doi: $10.1080 / 13504850110067450$

Benarroch, M., Pandey, M. (2012). The Relationship between Trade Openness and Government Size: Does Disaggregating Government Expenditure Matter?. Journal of Macroeconomics, 34, 239-252. doi: 10.1016/j.jmacro.2011.11.002

Breusch, T. S., Pagan, A. R. (1980). The Lagrange Multiplier Test and Its Applications to Model Specification In Econometrics. The Review of Economic Studies, 47(1), 239-253. doi: 10.2307/2297111
Cameron, D. R. (1978). The Expansion of the Public Economy. American Political Science Review, 72(4), 1243-1261. doi: 10.2307/1954537

Choi, I. (2001). Unit Root Tests for Panel Data. Journal of International Money and Finance, 20(2), 249272. doi: 10.1016/S0261-5606(00)00048-6

Dreher, A., Sturm, J. E., Ursprung, H. W. (2008). The Impact of Globalization on the Composition of Government Expenditures: Evidence from Panel Data. Public Choice, 134(4), 263-292. doi: 10.1007/ s11127-007-9223-4

Gadea, M. D., Sabate, M., Saenz, E. (2009). The Relationship between Trade Openness and Public Expenditure. The Spanish Case, 1960-2000. DTECONZ, 6, 1-50. doi: 10.1177/0015732513515987

Gemmel, N., Kneller, R., Snaz, I. (2008). Foreign Investment, International Trade and the Size and Structure of Public Expenditures. European Journal of Political Economy, 24, 151-171. doi: 10.1016/j.ejpoleco.2007.06.004

Genç, M. C., Telatar, O. M. (2015). Telafi Hipotezi Türkiye için Geçerli mi?. International Conference on Eurasian Economies, 437-444. urls'si. https:// www.avekon.org/papers/1380.pdf, Erişim Tarihi 26 Temmuz 2016

Jeannneney, S. G., Hua, P. (2004). Why do more Open Chinese Provinces have Bigger Governments?. Review of International Economics, 12(3), 525-542. doi: 10.1111/j.1467-9396.2004.00465.x

Jettera, M., Parmeter, C. F. (2015). Trade Openness and Bigger Governments: The Role of Country Size Revisited. European Journal of Political Economy, 37, 49-63. doi: 10.1016/j.ejpoleco.2014.11.001

Kimakova, A. (2009). Government Size and Openness Revisited: The Case of Financial Globalization. KYKLOS, 62(3), 394-406. doi: 10.1111/j.14676435.2009.00442.x 
Liberati, P. (2007). Trade Openness, Capital Openness and Government Size. Journal of Public Policy, 27 (2), 215-247. doi: 10.1017/S0143814X07000670

Maddala, G. S., Wu, S. (1999). A Comparative Study of Unit Root Tests with Panel Data and a New Simple Test. Oxford Bulletin of Economics and Statistics, 61(1), 631-652. doi: 10.1111/1468-0084.0610s1631

McCoskey, S., Kao, C. (1998). A Residual-Based Test of the Null of Cointegration in $\mathrm{Pa}$ nel Data. Econometric Reviews, 17, 57-84. doi: 10.1080/07474939808800403

Molana, H., Montagna, C., Violato, M. (2004). On the Causal Relationship between Trade Openness and Government Size: Evidence from 23 OECD Countries. University of Dundee. Discussion Paper, 164, 1-18. doi: $0.2139 /$ ssrn.716164

Narayan, P. K., Smyth, R. (2008). Energy Consumption and Real GDP in G7 Countries: New Evidence from Panel Cointegration with Structural Breaks. Energy Economics, 30, 2331-2341. doi: 10.1016/j. eneco.2007.10.006

Peacock, A. T., Wiseman, J. (1967). The Growth of Public Expenditure in the United Kingdom. Princeton University Press. url'si. http://www.nber.org/books/peac61-1

Pesaran M. H. (2004). General Diagnostic Tests for Cross Section Dependence in Panels. Cambridge Working Papers in Economics No. 435, University of Cambridge, and CESifo Working Paper Series No. 1229. doi: 10.17863/CAM.5113

Pesaran, M. H. (2006). Estimation and Inference in Large Heterogeneous Panels with a Multifactor Error Structure. Econometrica, 74(4), 967-1012. doi: 10.1111/j.1468-0262.2006.00692.x

Pesaran, M. H., Ullah, A., Yamagata, T. (2008). A Bias-Adjusted LM Test of Error Cross-Section Independence. Econometrics Journal, 11, 105-127. doi: 10.1111/j.1368-423X.2007.00227.x
Pesaran, M. H., Yamagata, T. (2008). Testing Slope Homogeneity in Large Panels. Journal of Econometrics, 142, 50-93. doi: 10.1016/j.jeconom.2007.05.010

Ram, R. (2009). Openness, Country Size, and Government Size: Additional Evidence from a Large Cross-Country Panel. Journal of Public Economics, 93, 213-218. doi: 10.1016/j.jpubeco.2008.04.009

Reis Mourão, P. (2007). Has Trade Openness Increased all Portuguese Public Expenditures? A Detailed Time-Series Study. Financial Theory and Practice, 31,(3), 225-247. urls’si., Erişim Tarihi 26 Ekim 2017

Rodrik, D. (1998). Why do more Open Economies have Bigger Governments?. The Journal of Political Economy, 106(5), 997-1032. doi: 10.1086/250038

Sáenz, E., Sabaté, M., Gadea, M. D. (2013). Trade Openness and Public Expenditure. The Spanish Case, 1960-2000. Public Choice, 154, 173-195. doi: 10.1007/s11127-011-9841-8

Sener, S., Bayrakdar, S., Hacioğlu, V. (2015). The Analysis for the Validity of Compensation and Efficiency Hypotheses in Turkey between 1975 and 2013. Procedia-Social and Behavioral Sciences, 195, 624-631. doi: 10.1016/j.sbspro.2015.06.143

Shahbaz, M., Rehman, H. U., Amir, N. (2010). The Impact of Trade and Financial-Openness on Government Size: A Case Study of Pakistan. Journal of Quality and Technology Management, 6 (1), 105-118. urls'si. http://www.ciitlahore.edu.pk/Papers/430-8589027356946163028.pdf, Erişim Tarihi 28 Temmuz 2016

Taşar, İ. (2016). Türkiye'de Etkinlik ve Telafi Edici Etki Hipotezlerinin Geçerliliğinin Test Edilmesi. Kahramanmaraş Sütçü İmam Üniversitesi İktisadi ve İdari Bilimler Fakültesi Dergisi, 6(2), 15-22. urls'si. http://iibfdergisi.ksu.edu.tr/download/article-file/264632, Erişim Tarihi 26 Ekim 2017 
Tuncer, G. (2016). Telafi Hipotezinin Türkiyede Geçerliliği: Bölgesel Panel Veri Analizi. Sosyal Bilimler Dergisi, 48, 144-154. urls'si. http://dergipark. gov.tr/dpusbe/issue/26800/283338, Erişim Tarihi 29 Temmuz 2016

Wagner, A. (1883). Three Extracts on Public Finance. Musgrave, A.R., Peacock, A.T., (ed.) (1967), Classics in the Theory of Public Finance. doi: 10.1007/978-1-349-23426-4_1

Westerlund, J. (2006). Testing for Panel Cointegration with Multiple Structural Breaks. Oxford Bulletin of Economics and Statistics, 68 (1), 101-132. doi: 10.1111/j.1468-0084.2006.00154.x
Zeren, F., Ergün, S. (2013). Ticari Açıklık ve Kamu Büyüklüğü İlişkisi: Panel Nedensellik Testi. Atatürk Üniversitesi İktisadi ve İdari Bilimler Dergisi, 27(4), 229-240. urls'si. http://e-dergi.atauni.edu.tr/ atauniiibd/article/view/1025009567/1025007794, Erişim Tarihi 29 Temmuz 2016

Zortuk, M., Beşer, B. (2014). Dışa Açıklık ve Demokratik Yapının Kamu Kesimi Büyüklüğü Üzerindeki Etkisi: Rodrik Hipotezine Geçiş Ekonomilerinden Kanıt. Ege Akademik Bakış, 14 (3), 345-359. doi: 10.21121/eab.2014318022 